\title{
Acrílico termopolimerizable enriquecido con nanopartículas de cobre: evaluación antibacteriana y citotóxica
}

\section{Thermo-polymerizable acrylic enriched with copper nanoparticles: Antibacterial and cytotoxic evaluation}

\author{
Liliana Argueta-Figueroa, 1,* Daniela Itzel Mesta-Pichardo,* \\ Nayely Torres-Gómez, ${ }^{* *}$ O. Martínez-Alvarez, ${ }^{* * *}$ \\ Ángel David Paulino-González, ${ }^{*}$ M. C. Arenas-Arrocena ${ }^{2, *}$
}

\begin{abstract}
The objective of this study was to determine the bacterial inhibition on S. aureus, E. coli and E. faecalis, as well as the cytotoxicity of thermo-polymerizable acrylic (PMMA) enriched with copper nanoparticles (CU NPS) on human gingival fibroblasts. Cu NPS are an area of interest in dentistry especially for its potential antibacterial effect. PMMA is one of the materials whose use is very widespread in current dental practice, but it has bacterial and fungal proliferation, which is why it is necessary to look for new strategies for its improvement. The data obtained in the present study show that the incorporation of CU NPS in the surface of the PMMA improves its antibacterial properties, either through the inhibition of the bacterial growth, as well as in the bacterial adhesion to its surface. In addition, it exhibits adequate cytotoxicity since it turned out to be light to moderate. Due to the above, this material could be an option to be used in removable prosthesis bases of thermocurable PMMA.
\end{abstract}

KEYWORDS: copper nanoparticles, acrylic resins, bacterial growth, cell viability, biocompatibility.

Recibido: 10 de enero de 2018.

Aceptado: 28 de abril de 2018.

${ }^{1}$ Liliana Argueta-Figueroa agradece a DGAPA-UNAM por la beca posdoctoral brindada. Gracias por el financiamiento otorgado a través de PAPIIT IN225516 y IA204516. PAPIME: PE210616, PE201617 y PE208518; SENER-CONACyT proyecto no. 207450 (CEMIE-Sol/27), CONACyT-México (CB176450) y SENER-CONACyT (245811), y Red Farmoquímicos de CONACyT. Gracias a Uvaldo Hernández-Balderas, por el análisis XRD realizado en CCIQS UAEMUNAM, y a Marina Vega-González por el soporte técnico.

${ }^{2}$ Autor para correspondencia: (carenas@enes.unam.mx), (mcaa05@gmail.com).

* Universidad Nacional Autónoma de México, Escuela Nacional de Estudios Superiores Unidad León, Área de Nanoestructuras y Biomateriales, Laboratorio de Investigación Interdisciplinaria, León, Guanajuato, México.

** Universidad Autónoma del Estado de México-Universidad Nacional Autónoma de México, Centro Conjunto de Investigación en Química Sustentable, Toluca, Estado de México, México.

*** Consejo Nacional de Ciencia y Tecnología, Ciudad de México, México. 
Mundo Nano | ARTíCULOS | www.mundonano.unam.mx

11(21), 45-60, julio-diciembre 2018 | http://dx.doi.org/10.22201/ceiich.24485691e.2018.21.62549

L. Argueta-Figueroa, D. I. Mesta-Pichardo, N. Torres-Gómez, O. Martínez Álvarez, A. D. Paulino-González, M. C. Arenas-Arrocena

RESUMEN: El objetivo de este estudio fue determinar la inhibición bacteriana sobre S. aureus, E. coli y E. faecalis, así como la citotoxicidad de acrílico termopolimerizable (PMMA) enriquecido con nanopartículas de cobre (CU NPS) sobre fibroblastos gingivales humanos Las CU NPS resultan un área de interés en odontología especialmente por su potencial efecto antibacterial. El PMMA es uno de los materiales cuyo uso se encuentra muy difundido en la actual práctica odontológica, pero presenta proliferación bacteriana y fúngica, por lo cual es necesario buscar nuevas estrategias para su mejoramiento. Los datos obtenidos en el presente estudio muestran que la incorporación de Cu NPS en la superficie del PMMA mejora sus propiedades antibacterianas, ya sea a través de la inhibición del crecimiento bacteriano, así como en la adhesión bacteriana a su superficie. Además, exhibe adecuada citotoxicidad ya que ésta resultó ser de ligera a moderada. Debido a lo anterior, este material podría ser una opción para ser empleado en bases de prótesis removibles de PMMA termocurable.

PALABRAS CLAVE: nanopartículas de cobre, resinas acrílicas, crecimiento bacteriano, viabilidad celular, biocompatibilidad.

\section{Introducción}

Las resinas acrílicas son polímeros muy utilizados en odontología, pues constituyen un material costeable, accesible y de fácil manipulación. (Frazer et al., 2005). Las resinas acrílicas de interés en odontología son las derivadas del ácido acrílico y del ácido metacrílico, que polimerizan por adición y presentan propiedades adecuadas en cuanto a su estabilidad fisicoquímica, manipulación y estética (Pfeiffer y Rosenbauer, 2004). El acrílico termopolimerizable es uno de los materiales cuyo uso se encuentra más difundido en la actual práctica odontológica, con éste se fabrican, usualmente, tanto dientes provisionales como bases para dentaduras parciales o totales, mediante la polimerización de partículas de polvo de polimetilmetacrilato (PMMA) prepolimerizado mezcladas con monómero de metacrilato de metilo (MMA) (Wieckiewicz et al., 2016). Sin embargo, la frecuente colonización de las superficies acrílicas puede generar la presencia de inflamación, dolor e infecciones que afectan a los pacientes que han sido rehabilitados con este material. Diferentes especies de Candida y de bacterias se han aislado del 63.3\% de las prótesis y de los tejidos bucales de los pacientes desdentados en comparación con aquellos pacientes que conservan sus dientes (Abbas A. Jafari et al., 2014). Debido a esto, la búsqueda de nuevas estrategias para la mejora de este material es indispensable (Arenas-Arrocena et al., 2017).

El desarrollo en la manufactura de este tipo de polímeros es notable y se ve favorecido por los avances tecnológicos actuales, resultando de particular interés para áreas emergentes y prometedoras como la nanotecnología en donde en fechas recientes las investigaciones se han enfocado en el desarrollo de polímeros combinados con NPs metálicas (Allaker y Memarzadeh, 2014). La nanotecnología es considerada una tecnología reciente que partiendo de dimensiones de 1 a $100 \mathrm{~nm}$ manipula los materiales con la finalidad de mejorar el diseño, elaboración y propiedades de los mismos a nivel macroscópico (European-Commission 2014). 
Con base en la nanoescala antes referida las partículas esféricas dentro de este rango son denominadas nanopartículas (NPs) y éstas poseen propiedades únicas en relación con su naturaleza, tamaño, distribución, morfología y tendencia a la aglomeración (Uskokovic, 2013). Si bien la nanotecnología se ha visto inmersa en todos los campos de la odontología, destaca principalmente su aplicación en la elaboración de materiales de restauración para potenciar sus propiedades y conferirles otras deseables, como propiedades antibacterianas; este potencial efecto resulta de particular interés en materiales que se utilicen para aplicaciones clínicas que impliquen un mayor riesgo para el desarrollo y crecimiento bacteriano, como lo son las bases para dentaduras (Hannig y Hannig, 2013).

Las nanopartículas metálicas más utilizadas y estudiadas en cuanto a su efecto antibacterial son las de dióxido de titanio, plata y óxido de zinc. Sin embargo en fechas recientes las nanopartículas de cobre ( $\mathrm{Cu}$ NPs) han resultado un área de interés debido a sus propiedades antimicrobianas y antifúngicas, lo que lo hace un elemento promisorio y potencialmente viable para distintas aplicaciones(Camacho-Flores et al., 2015). En un estudio in vitro evaluó la actividad antimicrobiana de las Cu NPs y se encontró que la concentración mínima inhibitoria (MIC) fue de $10 \mu \mathrm{g} / \mathrm{ml}$ para E. coli, mientras que para $S$. aureus y S. mutans fue de $100 \mu \mathrm{g} / \mathrm{ml}$. (Argueta-Figueroa et al., 2014), sin embargo no se evaluó la biocompatibilidad. Al revisar la literatura es notorio que se ha determinado dicha actividad antimicrobiana en las nanopartículas metálicas, pero es infrecuente que también se evalué simultáneamente su citotoxicidad. En otro estudio, se determinó la citotoxicidad en células provenientes de la epidermis de la piel humana de micropartículas y NPs de óxido de cobre (II) $(\mathrm{CuO})$ así como de cloruro de cobre $\left(\mathrm{CuCl}_{2}\right)$, con fines de comparación, el contenido de cobre en todos los grupos fue equivalente a $0.21 \mathrm{mg} /$ $\mathrm{ml}$ (170 ppm) y se encontró que la viabilidad celular disminuyó al $50 \%$ con las micropartículas de $\mathrm{CuO}$, al $87 \%$ con NPs de $\mathrm{CuO}$, y al $83 \%$ con $\mathrm{CuCl}_{2}$ (Cohen et al. 2013). Sin embargo, se ha postulado que el análisis del impacto biológico y los posibles efectos citotóxicos de los materiales, y en especial de las nanopartículas, debido a sus interacciones a nivel celular, deben ser determinados a la par, con la finalidad de ponderar el riesgo-beneficio de dichos materiales para un uso eficiente y responsable (García-Contreras et al., 2015).

Por lo tanto, el propósito de este estudio fue determinar la inhibición bacteriana (sobre S. aureus, E. coli y E. faecalis) así como la citotoxicidad (sobre fibroblastos gingivales humanos) de acrílico termopolimerizable (PMMA) enriquecido con nanopartículas de cobre.

\section{Material y método}

\section{Materiales}

Cloruro de cobre $\left(\mathrm{CuCl}_{2}\right.$, Sigma-Aldrich, St Luis, MO, EUA.), borohidruro de sodio $\left(\mathrm{NaBH}_{4}\right.$, Sigma-Aldrich), citrato de sodio $\left(\mathrm{Na}_{3} \mathrm{C}_{6} \mathrm{H}_{5} \mathrm{O}_{7}\right.$, Sigma-Al- 
drich), alcohol isopropílico (Karal, S. A. de C. V. León, Gto., México), yeso (Tipo IV, Manufacturera Dental Continental S. A. de C. V. México), separador yeso-yeso (Mcd dental, Zapopan, Jal. México), acrílico termopolimerizable (PMMA, Opticryl, New Stetic, Powerline Road, Florida, EUA), metilmetacrilato (Opticryl, New Stetic), caldo Mueller-Hinton (Sigma-Aldrich), agar Mueller-Hinton (Sigma-Aldrich), 3-(4,5- dimetiltiazol-2-ilo)-2,5-difeniltetrazol (мTт, Sigma-Aldrich), dimetilsulfóxido (DMSO, J. T. Baker, Phillipsburg, NJ, EUA), Alfa Modificación del Medio de Eagle ( $\alpha$-MEM, Life Technologies, Gibco ${ }^{\circledR}$, Gran Island, NY, EUA), suero fetal bovino (FBS, Life Technologies, Gibco ${ }^{\circledR}$ ), penicilina/estreptomicina (Life Technologies, Gib$\mathrm{Co}^{\circledR}$ ) y Glutamax (Life Technologies, Gibco ${ }^{\circledR}$ ), tripsina (Life Technologies, Gibco $^{\circledR}$ ), EDTA-2Na (Life Technologies, Gibco ${ }^{\circledR}$ ), solución buffer (PBS(-), Life Technologies, Gibco ${ }^{\circledR}$.

\section{Sintesis de las nanopartículas de cobre}

La síntesis de $\mathrm{Cu}$ NPs se realizó mediante el método de reducción química de acuerdo con un método previamente reportado (Argueta-Figueroa et al., 2014) con ligeras modificaciones; se empleó $\mathrm{CuCl}_{2}$ como precursor, $\mathrm{NaBH}_{4}$ como agente reductor y citrato de sodio como agente estabilizador, este último se agregó a la solución de las nanopartículas de cobre cuando la reacción se completó y se mantuvo en agitación por 10 minutos más. El producto obtenido, se lavó con acetona tres veces con el propósito de retirar residuos de la reacción. Las nanopartículas se suspendieron en agua deionizada, alcohol isopropílico, o se secaron a $60^{\circ} \mathrm{C}$ antes de realizar los análisis correspondientes de acuerdo a la naturaleza de cada prueba como se describe a continuación en las secciones posteriores.

\section{Caracterización de nanopartículas}

Se llevó a cabo la caracterización de las nanopartículas de cobre suspendidas en solución acuosa a través del análisis Uv-vis, empleando un espectrofotómetro (Thermo Scientific, St. Luis, MO, EUA). El espectro obtuvo en un rango de $400-800 \mathrm{~nm}$.

El análisis de tamaño de partícula y morfología se realizó mediante microscopía de transmisión electrónica, TEM (JEOL mod. JEM-1010). Las nanopartículas de cobre se suspendieron en alcohol isopropílico, se sonicaron durante media hora y se colocó una gota en una rejilla de cobre recubierta con fomvar y carbono para la obtención de las micrografías.

Por otro lado, la fase cristalina y la composición de las nanopartículas de cobre se determinaron a través de difracción de rayos $\mathrm{X}$ (DRX), utilizando un difractómetro Bruker D8 Advance de rayos X (Frankfurt, Alemania), operado a $35 \mathrm{kV}, 30 \mathrm{~mA}$, con radiación CuKa1 (longitud de onda $\lambda=1,5406 \AA$ ) $\mathrm{y}$ filtro de cobre. El difractograma de rayos $\mathrm{X}$ se obtuvo en un rango de $2 \theta$ de $0^{\circ}$ a $80^{\circ}$ con una velocidad de paso de $0.049^{\circ}$. 


\section{Procesamiento de los discos de acrílico termopolimerizable (PMMA)}

Se fabricaron discos de cera rosa toda estación con un tamaño de $15 \mathrm{~mm}$ de diámetro con un grosor de $3 \mathrm{~mm}$, lo cual permitió que los discos fueran colocados en los pocillos de la microplaca de 24 pocillos. Se pulieron los discos de cera con espátula de lecrón y se alisaron con monómero y gasas. Todas las superficies internas de la mufla se aislaron con petrolato para evitar que el yeso se adhiriera a ellas. Se vertió yeso tipo IV en la parte inferior de la mufla, se colocaron discos de cera, previa aplicación de petrolato en la superficie de los discos e introduciendo hasta la mitad del grosor de éstos para evitar retenciones.

Después de que el yeso fraguó, se aisló la superficie de éste con separador yeso-yeso y se inició una segunda fase de inclusión de yeso tipo IV cerrando con la mufla superior y cubriendo los discos con el yeso. Una vez terminado el tiempo de fraguado del yeso, se abrió la mufla y se retiraron los discos de cera. Se preparó PMMA termopolimerizable colocando el monómero en un recipiente de vidrio y sobre éste se adicionó el polímero en una relación de tres partes de polímero y una parte de monómero en volumen. El recipiente permaneció cerrado hasta que el acrílico alcanzó el estado filamentoso, entonces se colocó en la mufla, se cubrió con una lámina de polietileno y se cerró la mufla. La mufla se prensó en forma lenta hasta llegar a 1500 psi. Se descargó la prensa, se destapó la mufla y se removió la película de polietileno, retirando el excedente de acrílico. Se cerró nuevamente la mufla y se aplicó una presión definitiva de 2000 psi. Después del prensado final y todavía bajo presión, se instalaron los tornillos, hasta que éstos se apoyaron en la superficie de la mufla.

El horno de microondas que se empleó para la polimerización, debe tener una potencia mínima de 800 watts y máxima de 1300 watts. Se colocó la mufla sobre el plato giratorio dentro del horno, con los tornillos hacia abajo. En la primera fase, se programó el horno 3 minutos a una potencia de 40\%. En la segunda fase, se dejó 4 minutos con la mufla dentro del horno apagado. En la tercera fase, se programó el horno 3 minutos a la máxima potencia. Por último, se retiró la mufla del microondas y se colocó en una tina con agua fría, durante 45 minutos. Posteriormente, se retiraron los tornillos de la mufla y se separan cuidadosamente la mufla de la contramufla. Se eliminaron las irregularidades de la muestra dejando una superficie lisa y tersa con ayuda de lijas de agua grano fino.

\section{Recubrimiento del acrílico termopolimerizable (PMMA) con nanopartículas de cobre}

Los discos de acrílico se colocaron en el Spin Coater (Holmarc Opto-mechanics, modelo HO-TH-05, Kalamassery, India) y se recubrieron con $40 \mu \mathrm{l}$ de $\mathrm{Cu}$ NPs a diferentes concentraciones (31.5, 15.75, 7.875, 3.9375 y $0 \mu \mathrm{g})$. Se inició dicho recubrimiento colocando $40 \mu \mathrm{l}$ de la solución de las nanopartículas con el dispositivo funcionando a $1500 \mathrm{rpm}$ por $15 \mathrm{~s}$, posteriormente, a $1200 \mathrm{rpm}$ por otros $15 \mathrm{~s}$. Por último, se colocaron los discos en el horno a $60^{\circ} \mathrm{C}$ por $60 \mathrm{~s}$. 
Evaluación de la inhibición bacteriana en acrílico termopolimerizable (PMMA) con nanopartículas de cobre

Los experimentos sobre la actividad antimicrobiana se llevaron a cabo según lo descrito por el Instituto de Estándares Clínicos y de Laboratorio (CLSI) (Wikler 2009). La inhibición bacteriana de las Cu NPs en los discos de acrílico termopolimerizable (PMMA) se probó contra las bacterias patógenas humanas Staphylococcus aureus, Escherichia coli y Enterococcus faecalis determinando la concentración inhibitoria mínima (MIC) y la concentración bactericida mínima $(\mathrm{MBC})$ siguiendo el método de dilución en caldo. En una microplaca de 24 pocillos se colocaron los discos de acrílico con recubrimiento a diferentes concentraciones de $\mathrm{Cu}$ NPs, discos de acrílico sin recubrimiento, controles positivo y negativo, cada una por triplicado.

En cada pocillo se adicionó $1 \mathrm{~mL}$ caldo Mueller-Hinton. Previamente se habían empleado medios selectivos para cultivar cada cepa y después cada una se cultivó en medio no selectivo y se incubó a $37^{\circ} \mathrm{C}$ durante 24 h, el día previo al experimento, para obtener cultivos bacterianos frescos, los cuales se usaron para preparar el respectivo patrón de McFarland de cada cepa bacteriana. Cada patrón de McFarland se diluyó en relación 1:20 utilizando solución salina al $8 \%$. Después de la colocación de los discos en cada pocillo se inoculó cada uno asépticamente con la respectiva suspensión bacteriana (la concentración final fue de aproximadamente $5 \times 10^{5} \mathrm{CFU} / \mathrm{ml}$ ). Una vez inoculada, la microplaca se incubó a $37^{\circ} \mathrm{C}$ durante $24 \mathrm{~h}$, en una incubadora con agitación a $200 \mathrm{rpm}$. Se traspasaron $100 \mu \mathrm{l}$ de la solución de cada uno de los pocillos a una caja de 96 pocillos y se agregaron $100 \mu \mathrm{l}$ de MTT $(0.0002 \mathrm{~g} /$ $\mathrm{ml}$ ) disuelto en PBS en cada pocillo, se incubó la placa durante $4 \mathrm{~h}$ y se adicionaron $100 \mu \mathrm{l}$ de DMSO en cada pocillo. La presencia o ausencia de turbidez en cada pocillo se observó mediante el método MTT. La densidad óptica se leyó en un lector de microplaca (Thermo Scientific, St. Luis, MO, EUA) a $595 \mathrm{~nm}$.

Los resultados se expresaron como porcentaje de las bacterias viables en comparación con los controles no tratados. La concentración mínima de los pocillos que no mostraron turbidez (ausencia a simple vista de los cristales de formazano) se registró como MIC, para cada cepa bacteriana. El MBC se identificó mediante la determinación de la concentración más baja de agente antibacteriano que reduce la viabilidad del inóculo bacteriano inicial por $\geq 99.9 \%$ o $\geq 3$ log de reducción del recuento de inóculo. Para esto, se subcultivaron los pocillos en placas de agar Mueller-Hinton para corroborar los datos obtenidos a partir de la lectura de la densidad óptica antes mencionada.

Evaluación de la adhesión bacteriana en acrílico termopolimerizable (PMMA) con nanopartículas de cobre

Se realizaron experimentos de adhesión bacteriana utilizando cepas dos bacterianas gram-positivas (S. aureus y E. faecalis) y una cepa gram-negativa ( $E$. 
coli). La prueba de adhesión bacteriana se realizó como sigue: en una caja de 24 pocillos, se colocaron $6 \mathrm{ml}$ de caldo nutriente Mueller-Hinton en cada uno de los pocillos. Posteriormente se inocularon los pocillos con la respectiva cepa bacteriana a una concentración equivalente a 0.5 de McFarland, es decir, de $1 \times 10^{8} \mathrm{CFU} / \mathrm{mL}$. A continuación, los especímenes (discos de PMMA con nanopartículas de cobre a diferentes concentraciones, así como los controles de PMMA sin nanopartículas) se colocaron en los pocillos. Después de $24 \mathrm{~h}$ de incubación a $37^{\circ} \mathrm{C}$ bajo agitación continua a $100 \mathrm{rpm}$, se retiraron cuidadosamente los especímenes del medio, las bacterias adheridas se lavaron con PBS para retirar a aquellas bacterias que se encuentran no adheridas a los especímenes. Las bacterias adheridas a cada disco de PMMA se removieron con hisopos estériles y se cuantificaron mediante subcultivos de $100 \mu \mathrm{l}$ a una placa de agar Mueller-Hinton y se contaron las bacterias supervivientes después de $24 \mathrm{~h}$ de cultivo a $37^{\circ} \mathrm{C}$ como CFU. Cada experimento se repitió por triplicado.

\section{Evaluación de la citotoxicidad en acrílico termopolimerizable (PMMA) con nanopartículas de cobre}

Cultivo celular. Se subcultivaron fibroblastos gingivales humanos (HGF) en su división celular número 8 en un plato de $10 \mathrm{~cm}$ con $\alpha$-MEM, FBS, penicilina $100 \mathrm{UI} / \mathrm{mL}$, estreptomicina $100 \mathrm{mg} / \mathrm{ml}$ y 1\% de Glutamax. Las células se recogieron después mediante tratamiento con tripsina al $0.25 \%$, EDTA-2Na en $\operatorname{PBS}(-)$.

Ensayo de actividad citotóxica. Se inocularon células HGF $(2 \times 105$ células/ml) en cada pocillo de una microplaca de 24 pocillos y se incubaron durante $48 \mathrm{~h}$ para conseguir la adherencia y proliferación celular completa. En cada pocillo se colocan los discos de acrílico con recubrimiento a diferentes concentraciones de $\mathrm{Cu}$ NPs, discos de acrílico sin recubrimiento, controles positivo y negativo, cada uno por triplicado, se incubó por $24 \mathrm{~h}$. El porcentaje de células viables se determinó mediante el método MTT. Este método consiste en reemplazar el medio de cultivo con MTT $(0.2 \mathrm{mg} / \mathrm{ml})$ disuelto en DMEM y las células se incubaron durante $4 \mathrm{~h}$ a $37^{\circ} \mathrm{C}$. Después de sustituir el medio, el producto de formazano se disolvió con DMSO. Las células viables permanecen en el fondo de los pocillos, por lo que el sobrenadante se separa y se lava tres veces, después se realizan las lecturas de los pocillos a una absorbancia óptica de $570 \mathrm{~nm}$ usando un lector de microplacas. Adicionalmente, se obtuvieron imágenes en el microscopio óptico (Leica DMIL Led, Axi CAM MRC Zeiss, Alemania). El grado de citotoxidad se clasificó de acuerdo con la ISO 10993-5, Evaluación biológica de dispositivos médicos, Parte 5: pruebas de citotoxicidad in vitro, la cual clasifica como no citotóxico (viabilidad celular superior al 75\%), ligeramente citotóxica (viabilidad celular que varía entre $50 \%$ y $75 \%$ ), moderadamente citotóxica (viabilidad celular que varía entre $25 \%$ y $50 \%$ ) y severamente citotóxica (viabilidad celular inferior a $25 \%$ ). 


\section{Resultados y discusión}

\section{Caracterización}

El cobre, conocido desde hace mucho tiempo por su actividad antibacteriana y por su costo relativamente bajo, es un atractivo agente biocida (CamachoFlores et al., 2015). El coste económico de las NPs de cobre es bajo en comparación con otros nanomateriales metálicos como el oro y la plata. El uso práctico de las nanopartículas de $\mathrm{Cu}$ se enfrenta a la principal dificultad que surge de su inestabilidad debido a la oxidación que sufre en contacto con el ambiente. Además, la estabilidad coloidal de las nanopartículas así como su solubilidad en agua son factores indispensables para su potencial uso en aplicaciones biológicas. Por lo que el empleo de nanopartículas solubles en agua es necesario para asegurar su solubilidad en este medio. En lo que respecta a la caracterización de las nanopartículas de cobre, en la literatura se ha reportado que las nanopartículas de cobre metálico tienen una banda de absorción centrada en 570 y $600 \mathrm{~nm}$ asignada a la resonancia del plasmón superficial, pero debido a que el cobre se oxida fácilmente en condiciones ambientales, las nanopartículas podrían presentar una monocapa de óxido la cual puede ser identificada como una banda de absorción residual centrada en 800 nm (Khanna et al., 2007; Zhang et al., 2010; Silvester et al., 1991). En la figura 1, se observa un valor máximo en $593 \mathrm{~nm}$, por lo que podemos concluir que se obtuvieron nanopartículas de cobre metálico y que el surfactante utilizado evitó la oxidación, ya que no se observa la banda de $800 \mathrm{~nm}$ correspondiente al óxido de cobre.

En la figura 1b), se muestra la micrografía del producto de la síntesis de las nanopartículas de cobre recubiertas con el citrato, se distingue que las nanopartículas tiene una morfología similar y una distribución de tamaño uniforme. Se observa un aglomerado de nanopartículas poliedrales, las cuales presentan un tamaño promedio de menor a $20 \mathrm{~nm}$.

En la figura 1c) se muestra el patrón de difracción obtenido, los picos de difracción indexados (111), (200) y (220), indican la presencia de cobre metálico, al ser comparados con la tarjeta cristalográfica JCPDS 04-0836.

\section{Evaluación de la inhibición bacteriana en acrílico termopolimerizable (PMMA) con nanopartículas de cobre}

Las nanopartículas metálicas pueden incorporarse en la superficie de un polímero o incorporarse a la matriz. En particular, las nanopartículas de cobre han sido impregnadas en la superficie de fibras de algodón, látex y otros materiales poliméricos (Borkow y Gabbay, 2005).

Los resultados de este estudio pueden observarse en la figura 2, donde hay un efecto de inhibición del crecimiento bacteriano sobre las bacterias en estudio al estar en contacto con las nanopartículas de cobre sobre los discos de PMMA. En diversos estudios se ha mostrado que las técnicas actuales para procesar bases acrílicas para dentaduras producen cierto grado de porosi- 
FIGURA 1 a) Espectro Uv-vis de las nanopartículas de cobre. b) Micrografía de TEM en donde se aprecia la morfología y tamaño de las Cu NPS sintetizadas. c) Difractograma de las nanopartículas de cobre.

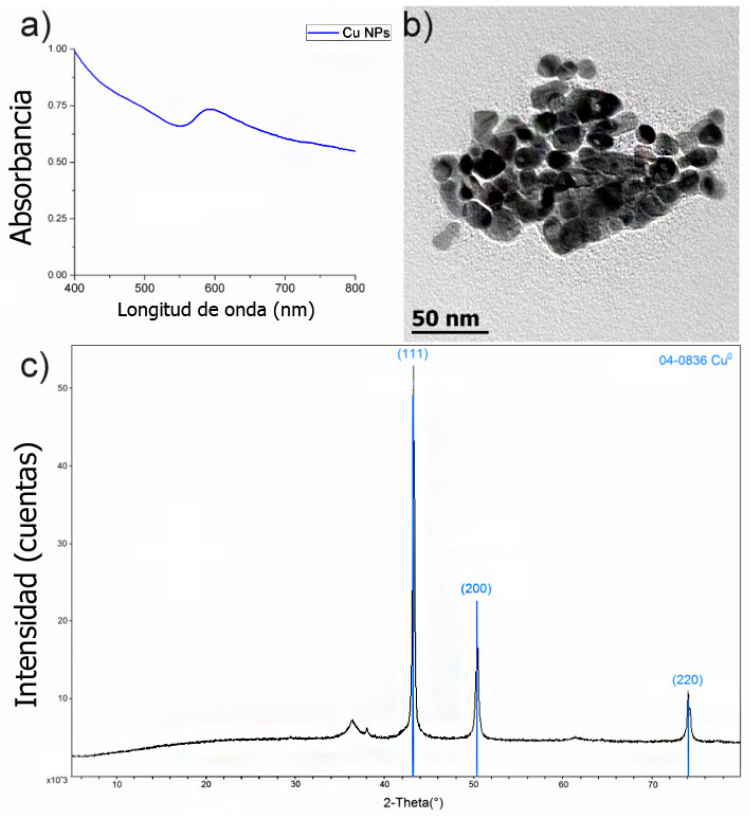

Fuente: Elaboración de los autores.

dades, las cuales permiten la colonización bacteriana (Lee, Lee y Nam, 2008). Una forma de abordar este problema es cubriendo la superficie de PMMA con nanomateriales que exhiban un efecto antimicrobiano. Desde la introducción de agentes antimicrobianos basados en nanopartículas, éstos han generado un gran interés (García-Contreras et al., 2011). Se han discutido diversos mecanismos para explicar la actividad de los materiales nanoestructurados, como la liberación de iones desde la superficie de las nanopartículas, la internalización a través de la pared celular, la producción de especies reactivas de oxígeno y el daño estructural a la membrana debido a vértices presentes en la morfología de las nanoestructuras (Lemire, Harrison y Turner, 2013; Fu et al., 2014; Mandal, 2016; Van Dong, Ha y Kasbohm, 2012). Por lo que resulta crucial la búsqueda de superficies que cuenten con efecto de inhibición bacteriana. A la máxima concentración de estudio, que fue $31.5 \mu \mathrm{g}$ por disco de PMMA, se encontró una reducción del crecimiento bacteriano de $99.9 \%$, $99.8 \%$ y $91.3 \%$ para $S$. aureus, E. coli y E. faecalis, respectivamente, lo que indica que existe una inhibición bacteriana considerable. En este estudio se emplearon S. aureus y E. coli como referentes para bacterias gram positivas y gram negativas, respectivamente.

Se observa en el presente estudio al igual que los resultados de otros reportes en la literatura que las bacterias gram positivas resultan más sensi- 
FIGURA 2. Gráfico de la inhibición del crecimiento bacteriano al estar en contacto con las nanopartículas de cobre sobre PMMA a diferentes concentraciones.

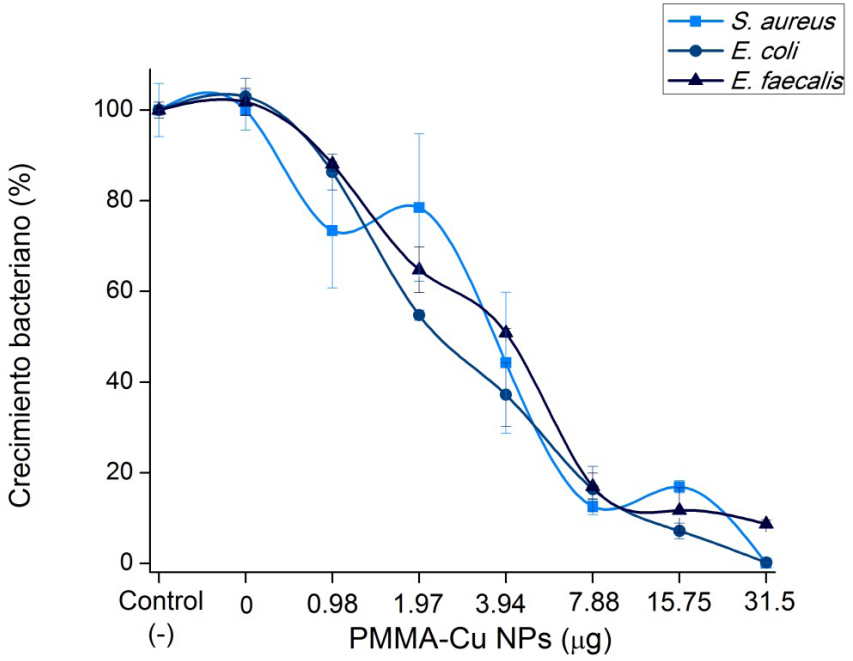

Fuente: Elaboración de los autores.

bles en comparación con las gram negativas a la acción de las nanopartículas, lo cual es atribuible al tipo de membrana. Mientras que las bacterias gram negativas presentan dos membranas lipídicas entre las que se localiza una fina pared celular de peptidoglicano, las bacterias gram positivas presentan una única membrana lipídica, siendo la pared de peptidoglicano mucho más gruesa. Sin embargo, la bacteria que se empleó por su resistencia a muchos agentes antibióticos fue E. faecalis. Dicha bacteria se caracteriza por resistir condiciones consideradas extremas, como ser capaz de sobrevivir en un medio con un $\mathrm{pH}$ de hasta 11 (McHugh et al., 2004). Por lo que el efecto de la inhibición bacteriana alcanzada en este estudio fue menor que en las dos bacterias mencionadas anteriormente; por lo tanto, para $E$. faecalis, el efecto del PMMA-Cu NPs puede considerarse bacteriostático. En otros estudios se ha reportado el uso de nanopartículas metálicas para proporcionar al PMMA un efecto antimicrobiano. Se ha determinado la inhibición bacteriana de PMMA-Cu NPs inmovilizadas con bentonita para $S$. aureus (ATCC 25123), y los autores concluyeron que este material exhibe un efecto bacteriostático para la cepa en estudio (Weickmann et al., 2005). Además se ha desarrollado un material de PMMA-dióxido de titanio $\left(\mathrm{TiO}_{2}\right)$ con actividad antibacteriana, para la fabricación de prótesis dentales impresas en 3D (Totu et al., 2017). Al parecer, el PMMA-TiO 2 (preparado por sol-gel) presenta un efecto antibacteriano fotoinducido para la reducción en el crecimiento bacteriano bajo la luz natural interior, pues casi el $100 \%$ de $S$. aureus y E. coli, se inactivaron con 2 horas de iluminación. En compa- 
ración con el PMMA sin ningún tratamiento, también se demuestra la capacidad superior de antiadhesión de la superficie de $\mathrm{PMMA}^{\mathrm{T}} \mathrm{TiO}_{2}$. (Su et al., 2010). Otras nanopartículas de óxido metálico que también se han utilizado para su integración a PMMA son las nanopartículas de dióxido de hierro. Estas nanopartículas mejoraron las propiedades antimicrobianas y mecánicas de las resinas acrílicas (Acosta-Torres et al., 2014). También se ha demostrado que la incorporación de nanopartículas en el PMMA resulta en un material biocompatible y que presenta buenas propiedades físicas y mecánicas (Moreno-Maldonado et al., 2012).

\section{Evaluación de la adhesión bacteriana en acrílico termopolimerizable (PMMA) con nanopartículas de cobre}

Se encontró que existe una disminución de la adhesión bacteriana de las cepas en estudio a la superficie de PMMA con nanopartículas cobre que es dosis-de-

FIGURA 3. Imágenes de los subcultivos que muestran la inhibición de la adhesión bacteriana al estar en contacto con nanopartículas de cobre sobre la superficie de PMMA a diferentes concentraciones.

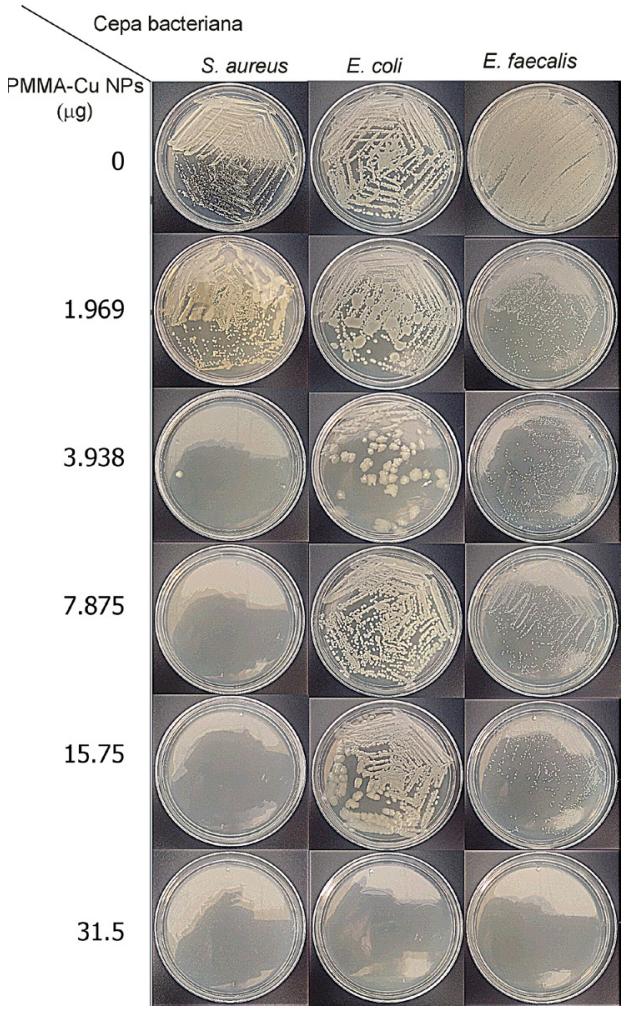

Fuente: Elaboración de los autores. pendiente, es decir, que a mayor concentración de las nanopartículas en la superficie de los discos de PMMA menor es la adhesión de las bacterias (figura 3). S. aureus fue la bacteria que presentó una mayor disminución en la adherencia sobre el PMMA-Cu NPs, mientras que E. coli y E. faecalis solamente no presentaron adherencia bacteriana a la concentración más alta (31.5 $\mu \mathrm{g}$ por disco).

En otros estudios previos, se ha observado que la adherencia de Candida albicans se redujo significativamente en el grupo de PMMA con nanopartículas de plata en comparación del PMMA sin nanopartículas (AcostaTorres et al., 2012). Además del efecto a través de los mecanismos antibacteriales propios de las nanopartículas, es posible que al colocarse las nanopartículas sobre la superficie del PMMA éstas ocupen los espacios de formados por las porosidades propias del procesamiento de este polímero. Dicho efecto físico a través de la reducción de la rugosidad sobre la superficie del PMMA también es posible que prevenga la adhesión bacteriana (Acosta-Torres et al., 2011). 
FIGURA 4. Gráfico de citotoxicidad de las nanopartículas de cobre en fibroblastos gingivales humanos (HGF) a diferentes intervalos de tiempo.

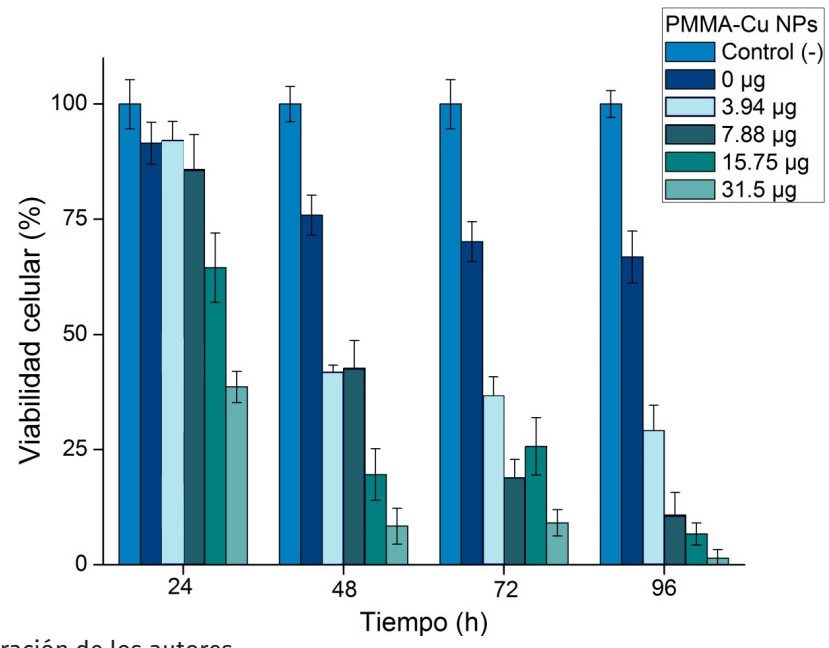

Fuente: Elaboración de los autores.

\section{Evaluación de la citotoxicidad en acrílico termopolimerizable (PMMA)} con nanopartículas de cobre

En la figura 4 puede observarse la viabilidad celular en los discos de acrílico termopolimerizable (PMMA). De acuerdo con la Norma ISO I10993-5 resultando que el PMMA sin nanopartículas, a las 24 horas, presenta una viabilidad superior al $75 \%$, por lo que se considera no citotóxico, sin embargo, a las 48, 72 y 96 h muestra una citotoxicidad ligera (viabilidad celular menor a $75 \%$ ). En general, a las 24 horas, se observa una citotoxicidad de ligera a moderada para las dos concentraciones más altas de nanopartículas sobre PMMA. Sin embargo, es evidente que la citotoxicidad aumenta conforme se incrementan los intervalos de tiempo. También se observa que, mientras mayor es la concentración de las nanopartículas, la viabilidad celular decrece, por lo tanto exhiben un comportamiento dosis-dependiente.

Se observa en las imágenes de microscopía óptica la viabilidad de HGF a intervalos de 24, 48, 72 y 96 h en función de la concentración del recubrimiento de las nanopartículas de cobre en los discos de PMMA (figura 5). Las bases para dentaduras formadas por resina acrílica de PMMA, que están en contacto con la mucosa oral del paciente, es un aspecto crítico para la biocompatibilidad en contacto con los tejidos, por lo cual resulta importante conocer el grado de citotoxicidad.

La citotoxicidad de PMMA se correlaciona con los métodos de polimerización, la temperatura, el ciclo de polimerización y el tiempo de almacenamiento de la resina acrílica puede influir en la cantidad de monómero residual y la citotoxicidad del material. El PMMA termopolimerizable en sí, presenta un cierto grado de citotoxicidad (Neves et al., 2013) lo cual concuerda con los resultados del presente estudio. 
FIGURA 5. Imágenes de microscopia óptica a una magnificación de 200x. Se observa la viabilidad de HGF a intervalos de $24,48,72$ y 96 h en función de la concentración del recubrimiento de las Cu NPS en los discos de acrílico termopolimerizable (PMMA). La barra de escala en cada imagen representa $5 \mu \mathrm{m}$.

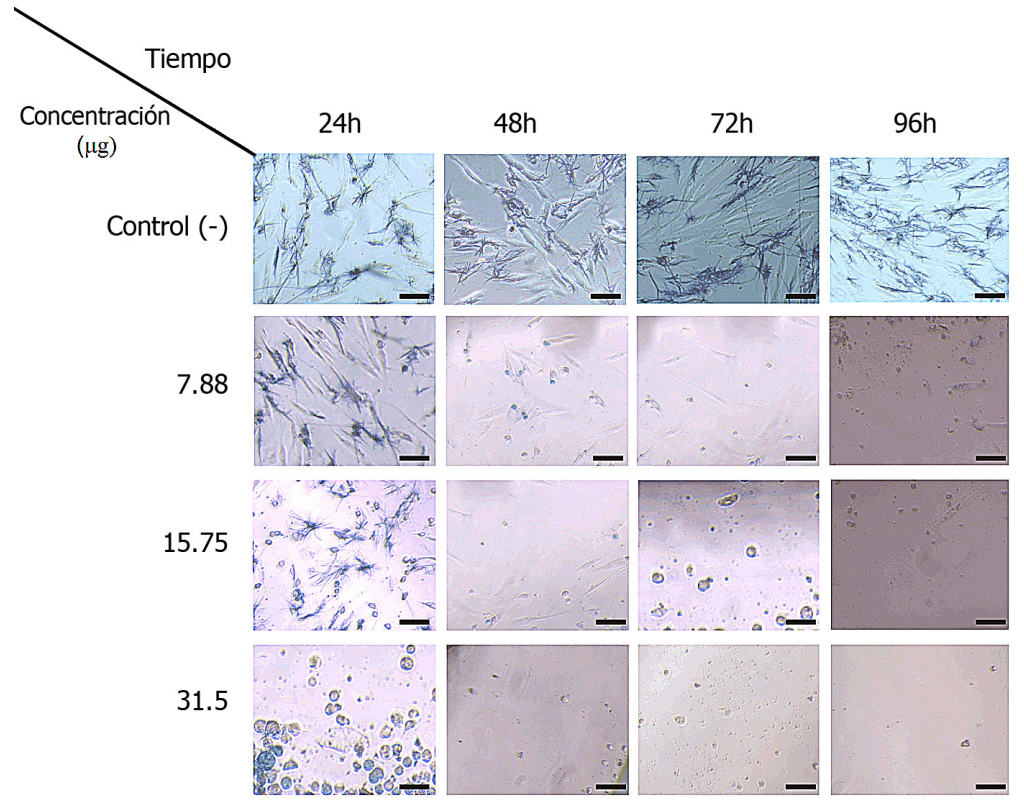

Fuente: Elaboración de los autores.

\section{Conclusiones}

Bajo las condiciones de este estudio, puede concluirse que la incorporación de nanopartículas de cobre en la superficie del PMMA termopolimerizable mejora sus propiedades a través de la inhibición del crecimiento bacteriano y la inhibición de la adhesión bacteriana en su superficie. El PMMA sin nanopartículas mostró una disminución en la viabilidad celular, la cual aumenta en función del tiempo de exposición. La citotoxidad que exhibió el PMMA enriquecido con nanopartículas de cobre exhibió una citotoxicidad dosis-dependiente, la cual también se incrementa en función del tiempo de exposición.

\section{Referencias}

Abbas Ali Jafari, Abbas Fallah-Tafti, Ali Fattahi-bafghi, Benafsha Arzy (2014). Comparison the occurrence rate of oral candida species in edentulous denture wearer and dentate subjects. International Journal of Medical Laboratory, 1(1): 15-21.

Acosta-Torres, L. S., Arenas, M. C., Nuñez-Anita, R. E., Barceló-Santana, F. H., Álvarez-Gayosso, C. A., Palacios-Alquisira, J., de la Fuente-Hernández, J., Cajero-Juárez, M y Castaño, V. M. (2014). Nanopigmented acrylic resin cured 
indistinctively by water bath or microwave energy for dentures. Journal of Nanomaterials, vol. 2014: 3. Hindawi Publishing Corp.

Acosta-Torres L. S., López-Marín, L. M., Nunez-Anita, R. E., Hernández-Padrón, G. y Castaño, V. M. (2011). Biocompatible metal-oxide nanoparticles: Nanotechnology improvement of conventional prosthetic acrylic resins. Journal of Nanomaterials, vol. 2011: 12. Hindawi Publishing Corp.

https://doi.org/10.1155/2011/941561

Acosta-Torres, L. S., Mendieta, I., Nuñez-Anita, R. E., Cajero-Juárez, M. y Castaño., V. M. (2012). Cytocompatible antifungal acrylic resin containing silver nanoparticles for dentures. International Journal of Nanomedicine, 7: 4777-4786.

https://doi.org/10.2147/IJN.S32391

Allaker, R. P. y Memarzadeh, K. (2014). Nanoparticles and the control of oral infections. International Journal of Antimicrobial Agents, 43(2): 95-104. https://doi.org/10.1016/j.ijantimicag.2013.11.002

Arenas-Arrocena, M. C., Argueta-Figueroa, L., García-Contreras, R., Martínez-Arenas, O., Camacho-Flores, B., Del Pilar Rodríguez-Torres, M., De la FuenteHernández, J. y Acosta-Torres, L. S. (2017). New trends for the processing of poly (methyl methacrylate) biomaterial for dental prosthodontics. En Acrylic Polymers in Healthcare, 1st ed, InTech, 43-74. https://doi.org/10.5772/intechopen.69066

Argueta-Figueroa, L., Morales-Luckie, R. A., Scougall-Vilchis, R. J. y Olea-Mejia, O. F. (2014). Synthesis, characterization and antibacterial activity of copper, nickel and bimetallic $\mathrm{Cu}-\mathrm{Ni}$ nanoparticles for potential use in dental materials. Progress in Natural Sciece-Materials International, 24(4): 321-328.

https://doi.org/10.1016/j.pnsc.2014.07.002

Borkow, G. y Gabbay, J. (2005). Copper as a biocidal tool. Current Medicinal Chemistry, 12(18): 2163-2175. Bentham Science Publishers.

https://doi.org/10.2174/0929867054637617

Camacho-Flores, B. A., Martínez-Álvarez, O., Arenas-Arrocena, M. C., García-Contreras, R., Argueta-Figueroa, L., De La Fuente-Hernández, J. y Acosta-Torres, L. S. (2015). Copper: Synthesis techniques in nanoscale and powerful application as an antimicrobial agent. Journal of Nanomaterials, 2015: 1-7.

https://doi.org/10.1155/2015/415238

Cohen, D., Soroka, Y., Ma'or, Z., Oron, M., Portugal-Cohen, M., Brégégère, F. M., Berhanu, D., Valsami-Jones, E., Hai, N. y Milner, Y. (2013). Evaluation of topically applied copper (II) oxide nanoparticle cytotoxicity in human skin organ culture. Toxicology in vitro, 27(1): 292-298, Elsevier.

https://doi.org/10.1016/j.tiv.2012.08.026

Van Dong, P., Ha, C. H. y Kasbohm, J. (2012). Chemical synthesis and antibacterial activity of novel-shaped silver nanoparticles. International Nano Letters, 2(1): 9, Springer.

European-Commission (2014). EU-European Commission Recommendation on the definition of nanomaterial. <http://osha.europa.eu/en/news/eu-europeancommissionrecommendation-on-the-definition-of-nanomaterial >

Frazer, R. Q., Byron, R. T., Osborne, P. B. y West, K. P. (2005). PMMA: An essential 
material in medicine and dentistry. Journal of long-term effects of medical implants, 15(6): 629-639.

https://doi.org/10.1615/JLongTermEffMedImplants.v15.i6.60

Fu, P. P., Xia, Q., Hwang, H.-M., Ray, P. C. y Yu, H. (2014). Mechanisms of nanotoxicity: Generation of reactive oxygen species', Journal of food and drug analysis, vol. 22, no. 1, Elsevier, 64-75. https://doi.org/10.1016/j.jfda.2014.01.005

García-Contreras, R., Argueta-Figueroa, L., Mejía-Rubalcava, C., Jiménez-Martínez, R., Cuevas-Guajardo, S., Sánchez-Reyna, P. A. y Mendieta-Zeron, H. (2011). Perspectives for the use of silver nanoparticles in dental practice. International Dental Journal, 61(6): 297-301.

https://doi.org/10.1111/j.1875-595X.2011.00072.x

García-Contreras, R., Sugimoto, M., Umemura, N., Kaneko, M., Hatakeyama, Y., Soga, T., Tomita, M., Scougall-Vilchis, R. J., Contreras-Bulnes, R., Nakajima, H. y Sakagami, H. (2015). Alteration of metabolomic profiles by titanium dioxide nanoparticles in human gingivitis model. Biomaterials, 57: 33-40.

https://doi.org/10.1016/j.biomaterials.2015.03.059

Hannig, M. y Hannig. C. (2013). Nanobiomaterials in preventive dentistry. En Subramani, K., Ahmed, W. y Hartsfield, J. K. (eds.), Nanobiomaterials in clinical Dentistry, 167-186.

Khanna, P. K., Gaikwad, S., Adhyapak, P. V., Singh, N. y Marimuthu, R. (2007). Synthesis and characterization of copper nanoparticles. Materials Letters, 61(25): 4711-4714, Elsevier. https://doi.org/10.1016/j.matlet.2007.03.014

Lee, C.-J., Lee, M.-S. y Nam, K.-Y. (2008). Inhibitory effect of PMMA denture acrylic impregnated by silver nitrate and silver nano-particles for Candida albicans. Journal of the Korean Chemical Society, 52(4): 380-386, Korean Chemical Society.

Lemire, J., Harrison, J. J. y Turner, R. J. (2013). Antimicrobial activity of metals: Mechanisms, molecular targets and applications. Nature Reviews. Microbiology, 11(6): 371-384. https://doi.org/10.1038/nrmicro3028

Mandal, B. K. (2016). Scopes of green synthesized metal and metal oxide nanomaterials in antimicrobial therapy. En Alexandru Grumezescu (ed.), Nanobiomaterials in antimicrobial therapy: Applications of nanobiomaterials. 210-300. https://doi.org/10.1016/B978-0-323-42864-4.00009-9

McHugh, C. P., Zhang, P., Michalek, S. y Eleazer, P. D. (2004). pH required to kill Enterococcus faecalis in vitro. Journal of endodontics, 30(4): 218-219, Elsevier.

https://doi.org/10.1097/00004770-200404000-00008

Moreno-Maldonado, V., Acosta-Torres, L. S., Barceló-Santana, F. H., VanegasLancón, R. D., Plata-Rodríguez, M. E. y Castano, V. M. (2012). Fiber-reinforced nanopigmented poly (methyl methacrylate) as improved denture base. Journal of Applied Polymer Science, 126(1): 289-296, Wiley Online Library.

https://doi.org/10.1002/app.36913

Neves, C. B., Lopes, L. P., Ferrão, H. F., Miranda, J. P., Castro, M. F. y Bettencourt, A. F. (2013). Ethanol postpolymerization treatment for improving the biocompatibility of acrylic reline resins. BioMed Research International, vol. 2013: 1-10. https://doi.org/10.1155/2013/485246 
Pfeiffer, P. y Rosenbauer, E.-U. (2004). Residual methyl methacrylate monomer, water sorption, and water solubility of hypoallergenic denture base materials. The Journal of prosthetic dentistry, 92(1): 72-78, Elsevier. https://doi.org/10.1016/S0022391304002057

Silvester, E. J., Grieser, F., Sexton, B. A. y Healy, T. W. (1991). Spectroscopic studies on copper sulfide sols. Langmuir, 7(12): 2917-2922, ACS Publications. https://doi.org/10.1021/la00060a009

Su, W., Wang, S., Wang, X., Fu, X. y Weng, J. (2010). Plasma pre-treatment and $\mathrm{TiO}_{2}$ coating of PMMA for the improvement of antibacterial properties. Surface and Coatings Technology, 205(2): 465-469. https://doi.org/10.1016/j.surfcoat.2010.07.013

Totu, E. E., Nechifor, A. C., Nechifor, G., Aboul-Enein, H. Y. y Cristache, C. M. (2017). Poly (methyl methacrylate) with $\mathrm{TiO}_{2}$ nanoparticles inclusion for stereolitographic complete denture manufacturing- the future in dental care for elderly edentulous patients? Journal of Dentistry, 59: 68-77, Elsevier. https://doi.org/ 10.1016/j.jdent.2017.02.012

Uskokovic, V. (2013). Entering the era of nanoscience: Time to be so small. Journal Biomed Nanotechnol, 9(9): 1441-1470. https://doi.org/10.1166/jbn.2013.1642

Weickmann, H., Tiller, J. C., Thomann, R. y Mülhaupt, R. (2005). Metallized organoclays as new intermediates for aqueous nanohybrid dispersions, nanohybrid catalysts and antimicrobial polymer hybrid nanocomposites. Macromolecular Materials and Engineering, 290(9): 875-883, Wiley Online Library. https://doi.org/10.1002/mame.200500153

Wieckiewicz, M., Wolf, E., Richter, G., Meissner, H. y Boening, K. (2016). New concept of polymethyl methacrylate (PMMA) and polyethylene terephthalate (PET) surface coating by Chitosan. Polymers, 8(132).

https://doi.org/10.3390/polym8040132

Wikler, M. A. (2009). Methods for dilution antimicrobial susceptibility tests for bacteria that grow aerobically. Clinical and Laboratory Standards Institute, Appproved Standard M7-A7, CLSI.

Zhang, Q.-L., Yang, Z.-M., Ding, B.-J., Lan, X.-Z. y Guo, Y.-J. (2010). Preparation of copper nanoparticles by chemical reduction method using potassium borohydride. Transactions of Nonferrous Metals Society of China, vol. 20, Elsevier, s240s244. https://doi.org/10.1016/S1003-6326(10)60047-7 